\title{
Subclinical neurological and neuropsychological effect of infection with HIV
}

\author{
C A CARNE,* C STIBE, $\dagger$ A BRONKHURST, $\ddagger$ S P NEWMAN, $\ddagger$ I V D WELLER*, \\ B E KENDALL, $\S$ M J G HARRISON $\dagger$
}

From the Academic Departments of *Genitourinary Medicine and $\ddagger$ Psychiatry, and the Departments of $\S$ Radiology and $\uparrow$ Neurology, Middlesex Hospital and Medical School, London

SUMMARY Thirty one homosexual men with antibody to human immunodeficiency virus (HIV) but without major neurological complaints were assessed in a cross sectional study of neurological and neuropsychological function. Eleven patients had AIDS, 10 had persistent generalised lymphadenopathy (PGL), and 10 had HIV infection without PGL (called "well"). Thirteen age matched homosexual men without antibody to HIV acted as controls. Significant abnormalities were found in six on clinical neurological examination, in eight on nerve conduction studies, in six on electroencephalography, in six on neuropsychological assessment, and in eight on computed tomography of the head. Eighteen patients (nine with AIDS, four with PGL, and five "well") performed abnormally in at least one section of the assessment. The study highlights the incidence of nervous system dysfunction in HIV infection even in people who do not have AIDS. Prospective evaluation using electrophysiological and imaging techniques is necessary to assess the natural history of such manifestations and the effect of antiviral treatment.

Human immunodeficiency virus (HIV) is generally accepted as the cause of the acquired immunodeficiency syndrome (AIDS), which is manifested as the development of opportunistic infections and neoplasms. The pathological effects of this virus are not confined to the immune system, however, and evidence is accruing that HIV is neurotropic as well as being tropic for lymphocytes and macrophages.

Early evidence for the presence of HIV in the brain was provided by infecting chimpanzees by inoculating them with brain tissue obtained at necropsy from patients with AIDS.' HIV specific DNA and RNA have also been shown in the brains of patients who died with AIDS encephalopathy. ${ }^{2}$ The virus has also been isolated from the brains and cerebrospinal fluid of patients with this condition, ${ }^{34}$ and HIV specific IgG has been shown within the blood brain barrier. ${ }^{56}$

HIV has been implicated as the direct cause of neurological manifestations, such as acute encephalitis, ${ }^{7}$ meningitis, ${ }^{4}$ myelopathy, ${ }^{8}$ and neuropathy, ${ }^{9}$ at

\footnotetext{
Address for reprints: Dr S P Newman, Department of Psychiatry, University College and Middlesex School of Medicine, Wolfson Building, Middlesex Hospital, Riding House Street, London WIN 8AA
}

Accepted for publication 6 January 1989 the time patients start to produce antibody to HIV, though each of these complications is rare. Neurological manifestations during chronic HIV infection are more common. Most reports have concerned subacute encephalopathy that causes dementia, ${ }^{10}$ but myelopathy" and peripheral neuropathy ${ }^{12}$ are also well recognised.

These manifestations have been observed mainly in patients with infections or tumours meeting the Centers for Disease Control (CDC) criteria for diagnosing AIDS, but also occur in others with HIV infection. The latest revision of the CDC definition of AIDS includes HIV encephalitis. The average latent period of some types of neurological diseases related to HIV infection may possibly be several or many years, in which case neurological disease may be seen more often in the future.

The antiviral agent, zidovudine, has been reported as possibly at least partially reversing neurological dysfunction induced by HIV.$^{13}$ The indications for the use of zidovudine may be said to include HIV infected patients with neurological disease. For this reason, and to monitor the progress of antiviral treatment, it is important to identify the most sensitive methods of detecting HIV induced neurological dysfunction, and to understand the prevalence and natural history of HIV induced neurological disease. 
To elucidate details of the onset of neurological effects we carried out a cross sectional study of men at different stages in the evolution of their chronic HIV infection. The data provide evidence about the incidence of subclinical dysfunction of the peripheral and central nervous systems and prompt speculation about the circumstances in which the virus is neurotropic.

\section{Patients and methods}

We studied the following groups of homosexual men: 11 patients with AIDS (mean age 38.3 (SD 6.6) years), of whom eight had survived one episode of Pneumocystis carinii pneumonia (PCP) and three had Kaposi's sarcoma (one of whom had had PCP); 10 with antibody to HIV and persistent generalised lymphadenopathy (PGL) (mean age 37.8 (SD 10.8) years) of at least two years' duration; 10 with antibodies to HIV who had not developed PGL (referred to as "well') (mean age 35.7 (SD 6.9) years); and $13 \mathrm{HIV}$ antibody negative age matched controls (mean age 34.8 (SD 9.5) years).

We recruited the controls and the patients with HIV, except those with AIDS, from a cohort study of the natural history of HIV infection that was being conducted in the academic department of genitourinary medicine at the Middlesex Hospital. Recruitment of the cohort had started in 1982 before testing for antibody to HIV became available. Three groups of men had been recruited; those with PGL, the regular sexual partners of patients with PGL, and men who had had 10 or more sexual partners in the previous three months. About two thirds of the two groups without PGL were found retrospectively to have antibodies to HIV. None of the patients recruited had major neurological complaints. One had hemiparesis of long standing caused by a birth injury, and another had a history of sciatica.

Patients with AIDS or antibody to HIV were interviewed and examined, using a standardised protocol, by a neurologist (MH in all but one of the cases). All were referred for non-enhanced computed tomography of the head (performed by BK), for routine electroencephalography (performed by $\mathrm{MH}$ ), and for a battery of neuropsychological tests (administered by $\mathrm{AB}$ ). The examiners were not given information about the clinical status of any patient when carrying out or reporting on electromyography, electroencephalography, or computed tomography. (The clinical examiners could not be "blinded" to the presence of Kaposi's sarcomata.) None of the patients was an intravenous drug abuser, an alcoholic, or receiving medication that could influence the clinical, neuropsychological, or neurophysiological findings.

The neurological examination was supplemented by measuring averaged antidromic sural sensory action potentials using surface electrodes over a $14 \mathrm{~cm}$ distance and a Medelec MS6 recorder. Vibration thresholds for the index of the dominant hand and the hallux of the dominant foot were recorded using a biothesiometer. A standard electroencephalogram was obtained using pad electrodes and the 10/20 system of electrode placement with the subjects in a resting state. A three minute period of hyperventilation was included at the end of the recording.

The neuropsychological assessment consisted of 10 tests, some of which were computer based. Neuropsychological assessment was performed on one occasion only, which limited the number of tests that could be performed. The vocabulary and picture completion subtests of the Wechsler adult intelligence scale were administered to gauge general intellectual level. Memory was assessed using the Rey auditory verbal learning test. ${ }^{14}$ Non-verbal memory was assessed by means of a computerised test that consisted of a chequerboard design presented to the patient for 10 seconds followed by three designs, one of which was identical to the original. There were two levels of difficulty for this test, each with 15 designs. The number of correct responses and the speed of response were recorded. ${ }^{15}$

Tracking ability was assessed by means of the trail making tests $A$ and $B,{ }^{16}$ and perceptuomotor abilities by the Purdue pegboard. ${ }^{17}$ Attention and concentration abilities were measured using a computerised two choice reaction time task, a letter cancellation task, and an automated symbol digit replacement task. ${ }^{15}$ The letter cancellation task required the subject to work as quickly as possible through an array of 90 letters, crossing out every occurrence of the letter " $p$ ". The symbol digit test required the subject to "type" the appropriate number that corresponded to a particular symbol. After 20 practice trials, 50 items were presented. In all these tests, we recorded speed and errors. The Wechsler adult intelligence scale block design subtest, which investigates visuospatial ability, was also administered.

We assessed the controls with the nerve conduction studies, the biothesiometer, and the battery of neuropsychological tests. The results obtained from the controls were used to define abnormal performance by the three groups of patients.

Although the neuropsychological tests were specifically designed to be insensitive to differences in education or general levels of intellectual ability, we compared the groups of patients to ensure that their general levels of intellectual ability were not different. Two tests from the Wechsler adult intelligence scale were performed to obtain a gross measure of general intellectual ability of all the groups. For the age of people under consideration in this study, the 
vocabulary subtest has a high correlation with the full verbal score of the Wechsler adult intelligence scale $(r=0.84-0.85)$, and the picture completion subtest has a similarly high correlation with performance score $(r=0.69-0.73)$. To compute the performance intelligence quotient (IQ) of each group the block design test, which was also performed, was included in the prorating for performance IQ. Analysis of the verbal and the performance IQs showed no significant differences between the groups.

\section{Results}

The routine enquiry for neurological symptoms showed that six of the subjects complained of sensory disturbance in hands or feet, or both. Two complained of dizziness and one of poor urinary control, one was recovering from recent Bell's palsy, and one from herpes zoster infection. Peripheral dysaesthesia was more common in the patients with AIDS (3/11) than in the "well" patients $(1 / 10)$, but the numbers were too small to be more than suggestive.
Neurological examination showed depressed tendon reflexes in three patients with AIDS and in one "well" patient (table 1). None had overt causes for peripheral neuropathy, and all were aged under 45 , so the reflex changes did not appear to be age related. One patient with PGL was ataxic and one "well" patient had poor balance. Only one patient (with AIDS) had sensory loss. He showed loss of joint position sense in the big toes and some distal impairment of the appreciation of light touch. This patient had an unmeasurably high vibration threshold on biothesiometry of the hallux. The readings for the other patients showed no differences from those for the control (with no antibody to HIV) age matched homosexual men.

Analysis of the amplitude of the antidromic sural sensory action potentials for the three groups of men infected with HIV and the control subjects showed a significant difference between groups (analysis of variance $F=3.3 ; p<0.05$ ). Post hoc tests showed mean amplitudes were significantly $(p<0.05)$ smaller in the men with AIDS (5.9 (SD 4.3)) than in those with

Table 1 Appreciable abnormalities in individual patients with AIDS or persistent generalised lymphadenopathy (PGL) or no symptoms ("well")

\begin{tabular}{|c|c|c|c|c|c|c|c|c|c|}
\hline Patients & & $\begin{array}{l}\text { Manifestations } \\
\text { of } A I D S\end{array}$ & $\begin{array}{l}\text { Duration } \\
\text { of } A I D S \\
\text { (months) }\end{array}$ & $\begin{array}{l}\text { Clinical } \\
\text { signs }\end{array}$ & $\begin{array}{l}\text { Sural } \\
\text { SAP }\end{array}$ & $E E G$ & $\begin{array}{l}\text { Neuro- } \\
\text { psychological }\end{array}$ & $C T$ & $V S$ \\
\hline AIDS: & $\begin{array}{l}1 \\
2 \\
3 \\
4 \\
5 \\
6 \\
7 \\
8 \\
9 \\
10 \\
11\end{array}$ & $\begin{array}{l}\text { Kaposi's sarcoma (KS) } \\
P \text { carinii pneumonia (PCP) } \\
\text { KS and PCP } \\
\text { PCP } \\
\text { PCP } \\
\text { PCP } \\
\text { KS } \\
\text { PCP } \\
\text { PCP } \\
\text { PCP } \\
\text { PCP }\end{array}$ & $\begin{array}{r}32 \\
4 \\
1 \\
4 \\
9 \\
8 \\
1 \\
11 \\
14 \\
13 \\
4\end{array}$ & $\begin{array}{l}\text { Depressed reflexes } \\
\text { Depressed reflexes } \\
\text { Depressed reflexes }\end{array}$ & $\begin{array}{l}\mathbf{X} \\
\mathbf{X} \\
\mathbf{X}\end{array}$ & $\begin{array}{l}\mathbf{X} \\
\mathbf{X} \\
\\
\mathbf{X} \\
\mathbf{X} \\
\mathbf{X}\end{array}$ & $\begin{array}{l}\mathbf{X} \\
\mathbf{X} \\
\mathbf{X} \\
\mathbf{X}\end{array}$ & $\begin{array}{l}\underset{\mathbf{X}}{\mathbf{X}} \\
\mathbf{X} \\
\mathbf{X}\end{array}$ & $\mathbf{X}$ \\
\hline PGL: & $\begin{array}{r}1 \\
2 \\
3 \\
4 \\
5 \\
6 \\
7 \\
8 \\
9 \\
10\end{array}$ & & & Ataxia & $\mathbf{X}$ & & $\mathbf{X}$ & $\mathbf{X}$ & $\mathbf{X}$ \\
\hline “Well” & $\begin{array}{r}1 \\
2 \\
3 \\
4 \\
5 \\
6 \\
7 \\
8 \\
9 \\
10\end{array}$ & & & $\begin{array}{l}\text { Poor balance } \\
\text { Depressed reflexes }\end{array}$ & $\begin{array}{l}\mathbf{x} \\
\mathbf{x}\end{array}$ & $\mathbf{X}$ & $\mathbf{X}$ & $\mathbf{X}$ & \\
\hline
\end{tabular}

$X=$ Abnormalities: on sural sensory action potential (SAP), mean amplitude below 5 microvolts; on electroencephalography (EEG), excess of theta activity or (in AIDS patients) unstable record; on neuropsychological assessment, two test results worse than 2 SDs from mean of HIV negative controls; on computed tomography (CT), atrophy, enlarged or assymetrical ventricles, prominent sulci, or evidence of cerebral infarct of unknown age; on vibration sense (VS) testing, threshold $>2$ SDs above mean of HIV negative controls. 
Table 2 Performances of seronegative controls and seropositive patients (symptomless ("well") or with persistent generalised lymphadenopathy (PGL) or AIDS) in neuropsychological tests (figures are mean (SD) times, scores, or numbers)

\begin{tabular}{|c|c|c|c|c|c|c|c|c|}
\hline \multirow{2}{*}{$\begin{array}{l}\text { Neuropsychological test } \\
\text { Letter cancellation (seconds) } \\
\text { Trail making A (seconds) } \\
\text { Trail making B (seconds) }\end{array}$} & \multicolumn{2}{|c|}{ Seronegative } & \multicolumn{2}{|c|}{ "Well" } & \multicolumn{2}{|l|}{$P G L$} & \multicolumn{2}{|l|}{$A I D S$} \\
\hline & $\begin{array}{r}204 \\
26 \\
79\end{array}$ & $\begin{array}{l}(54) \\
(10) \\
(35)\end{array}$ & $\begin{array}{r}197 \\
27 \\
73\end{array}$ & $\begin{array}{l}(76) \\
(10) \\
(32)\end{array}$ & $\begin{array}{c}180 \\
33 \\
94^{*}\end{array}$ & $\begin{array}{r}(35) \\
(7) \\
(44)\end{array}$ & $\begin{array}{r}210 \\
33 \\
113^{*}\end{array}$ & $\begin{array}{l}(80) \\
(13) \\
(62)\end{array}$ \\
\hline $\begin{array}{l}\text { Purdue pegboard: } \\
\text { Right (No) } \\
\text { Left (No) } \\
\text { Both (No) } \\
\text { Block design (raw score) }\end{array}$ & $\begin{array}{l}16 \\
15 \cdot 4 \\
12 \cdot 8 \\
40 \cdot 7\end{array}$ & $\begin{array}{l}(2 \cdot 1) \\
(2 \cdot 2) \\
(2 \cdot 0) \\
(8 \cdot 3)\end{array}$ & $\begin{array}{l}15 \cdot 4 \\
15 \cdot 6 \\
13 \cdot 1 \\
40 \cdot 4\end{array}$ & $\begin{array}{l}(1 \cdot 6) \\
(1 \cdot 1) \\
(1 \cdot 6) \\
(8 \cdot 2)\end{array}$ & $\begin{array}{l}15 \cdot 6 \\
14 \cdot 7 \\
12 \cdot 5 \\
40 \cdot 7\end{array}$ & $\begin{array}{l}(2 \cdot 1) \\
(1 \cdot 3) \\
(1 \cdot 4) \\
(6 \cdot 0)\end{array}$ & $\begin{array}{l}14 \cdot 7 \\
14 \cdot 3 \\
11 \cdot 8 \\
36 \cdot 5\end{array}$ & $\begin{array}{l}(2 \cdot 0) \\
(2 \cdot 05) \\
(2 \cdot 5) \\
(9 \cdot 9)\end{array}$ \\
\hline $\begin{array}{l}\text { Rey auditory verbal learning: } \\
\text { First recall (No) } \\
\text { Fifth recall (No) } \\
\text { Delayed recall (No) }\end{array}$ & $\begin{array}{r}8 \cdot 0 \\
13 \cdot 5 \\
11 \cdot 2\end{array}$ & $\begin{array}{l}(2 \cdot 0) \\
(1 \cdot 6) \\
(2 \cdot 5)\end{array}$ & $\begin{array}{r}8 \cdot 1 \\
13 \cdot 3 \\
11 \cdot 2\end{array}$ & $\begin{array}{l}(1 \cdot 5) \\
(1 \cdot 6) \\
(3 \cdot 2)\end{array}$ & $\begin{array}{r}8 \cdot 0 \\
12 \cdot 5 \\
11 \cdot 5\end{array}$ & $\begin{array}{l}(2 \cdot 4) \\
(2 \cdot 8) \\
(3 \cdot 4)\end{array}$ & $\begin{array}{r}11 \cdot 8 \\
12 \cdot 1 \\
9 \cdot 4\end{array}$ & $\begin{array}{l}(1 \cdot 8) \\
(1 \cdot 8) \\
(2 \cdot 3)\end{array}$ \\
\hline $\begin{array}{l}\text { Two choice reaction time: } \\
\text { Time (milliseconds) } \\
\text { Errors (No) }\end{array}$ & $\begin{array}{r}478 \\
0.9\end{array}$ & (98) & $\begin{array}{r}510 \\
0.9\end{array}$ & (97) & $\begin{array}{r}553 \\
1 \cdot 2\end{array}$ & (242) & $\begin{array}{r}734 \\
2 \cdot 2\end{array}$ & (432) \\
\hline $\begin{array}{l}\text { Symbol digit replacement: } \\
\text { Time (milliseconds) } \\
\text { Errors (No) }\end{array}$ & $\begin{array}{r}2510 \\
1.8\end{array}$ & (386) & $\begin{array}{r}2484 \\
1 \cdot 3\end{array}$ & $(622)$ & $\begin{array}{r}2775 \\
2 \cdot 3\end{array}$ & (914) & $\begin{array}{r}3020 \\
2 \cdot 6\end{array}$ & (885) \\
\hline $\begin{array}{l}\text { Non verbal memory test 1: } \\
\text { Time (milliseconds) } \\
\text { Errors (No) }\end{array}$ & $\begin{array}{r}3277 \\
1 \cdot 8\end{array}$ & (1502) & $\begin{array}{r}3702 \\
1 \cdot 3\end{array}$ & (1351) & $\begin{array}{r}4173 \\
2 \cdot 3\end{array}$ & (1123) & $\begin{array}{r}4040 \\
2 \cdot 6\end{array}$ & (1830) \\
\hline $\begin{array}{l}\text { Non-verbal memory test 2: } \\
\text { Time (milliseconds) } \\
\text { Errors (No) }\end{array}$ & $\begin{array}{r}3553 \\
0.9\end{array}$ & (1303) & $\begin{array}{l}3493 \\
1 \cdot 1\end{array}$ & (1347) & $\begin{array}{r}3531 \\
1 \cdot 8\end{array}$ & (702) & $\begin{array}{r}4073 \\
2\end{array}$ & $(1750)$ \\
\hline
\end{tabular}

*Significantly different from seronegative controls $(\mathrm{p}<0.05)$. See text for details.

PGL (14.1 (SD 6.7)) and the controls (12.8 (SD 8.0)). Although the "well" patients had larger amplitudes $(9 \cdot 2(6 \cdot 6))$ than those with AIDS, the difference did not achieve significance. There were no significant differences between the sensory latencies of the four groups.

Standard electroencephalograms showed a major slow wave abnormality in one patient with AIDS. One of the "well" patients also had a moderate excess of theta activity, which was considered to be a mild but definite abnormality. Unstable records either at rest or on overbreathing, were reported in four patients with AIDS, but in none of the others $\left(\chi^{2} 7.3 ; p<0.01\right)$. All but one of the AIDS patients showed some theta activity compared with seven of the 18 others $\left(\chi^{2} 6 \cdot 2 ; p\right.$ $<0.05$ ) (two patients failed to attend for electroencephalography). None of these changes could be related to current medication or to intercurrent illnesses.

The results of the neuropsychological examinations showed that men with AIDS performed less well than the other patients in almost all the tests (table 2). In most cases the results of the tests showed increasingly poorer performance with progression of the disease. This was particularly apparent in timed tests, such as the trail making, letter cancellation, choice reaction time, and symbol digit replacement tests. What was notable in the choice reaction time and symbol digit modalities tests was that the mean time for a correct response increased with disease progression as did the number of errors. This implied that the increased times did not reflect a trade off between speed and accuracy. The results of trail making test $B$ showed a significant difference between patients with PGL and controls and between patients with AIDS and controls (Duncan's multiple range test, $p<0.05$ ). Trail making test $B$ has been found to be particularly sensitive to the presence of brain damage. ${ }^{18}$ The failure to find significant differences in other test results reflects the relatively small sample size and the wide variability of performance. Regarding the variability of performance, in most of the tests the standard deviation of the performance was greatest in the patients with AIDS. This reflected the increased likelihood of poor scores by patients with AIDS. Consequently in the normative tests more patients with AIDS produced performances indicative of cognitive deficits. ${ }^{18}$

Computed tomograms showed abnormalities in 5/10 AIDS patients (one not scanned), 2/10 PGL patients, and $2 / 10$ "well" patients. The abnormalities in the patients with AIDS were diffuse cerebral atrophy (1), meningioma (1), minor enlargement of lateral ventricles $(2$, one of whom also had prominent sulci), and minor prominence of the cerebral sulci (1). One of the PGL patients had ventricular asymmetry with minor prominence of sulci, and one showed evidence of a cerebral infarct of unknown age. One "well" patient showed minor prominence of sulci, and one had mild cortical atrophy with scattered low density in the white matter, which suggested subacute HIV encephalitis. In each case the diagnosis of atrophy was made on the basis of age related norms.

In summary, 18 patients (nine with AIDS, four with PGL, and five "well") performed abnormally in at least one section of the assessment (table 1). In each 
Table 3 Appreciable abnormalities in groups of patients with AIDS or persistent generalised lymphadenopathy (PGL) or no symptoms ("well") (figures are numbers (percentages) of patients with abnormalities in each group)

\begin{tabular}{|c|c|c|}
\hline Abnormalities & $\begin{array}{l}A I D S \\
(n=11)\end{array}$ & $\begin{array}{l}\text { "Well" + } P G L \\
(n=20)\end{array}$ \\
\hline $\begin{array}{l}\text { Clinical } \\
\text { Sural sensory action potential } \\
\text { Electrocephalographic } \\
\text { Neuropsychological } \\
\text { Computed tomographic }\end{array}$ & $\begin{array}{ll}3 & (27 \cdot 3) \\
5 & (45 \cdot 5) \\
5 & (45 \cdot 5) \\
4 & (36 \cdot 4) \\
4 & (36 \cdot 4)\end{array}$ & $\begin{array}{ll}3 & (15) \\
3 & (15) \\
1 & (20) \\
2 & (10) \\
4 & (20)\end{array}$ \\
\hline
\end{tabular}

section of the assessment a higher percentage of men with AIDS than with PGL or no symptoms performed abnormally (table 3 ).

\section{Discussion}

Extensive experience of symptomatic patients with HIV infection has shown that neurological complications are numerous and diverse. In one unselected group of 318 patients, $124(39 \%)$ had neurological symptoms. ${ }^{12}$ Necropsy, however, has shown much larger percentages $\left(87 \%\right.$ in one series $\left.{ }^{19}\right)$ with nervous system complications, which suggests a high incidence of subclinical dysfunction. Neurological complications may arise as a result of opportunistic infections or tumours. In either circumstance the consequent disease is life threatening. HIV induced neurological dysfunction, however, is likely to be overlooked in the presence of systemic life threatening disease. HIV can affect the nervous system as early as at the time of seroconversion. In rare cases this is accompanied by florid disease, but the incidence of early subclinical dysfunction is not known.

We argued that a search for a subclinical effect on the nervous system would extend knowledge of the incidence of the neurological effect of HIV infection both before AIDS and in the full blown syndrome. It would also be valuable in highlighting neurological signs that might be used to monitor the progress of HIV damage in the nervous system and to assess the results of any therapeutic trials, such as those in progress with zidovudine.

The findings of this cross sectional pilot study in patients without major neurological complaints have shown that many men infected with HIV have detectable impairment of both the central and the peripheral nervous systems. In all, 18 of the 31 patients tested performed abnormally in at least one section of the assessment (the patient with a meningioma had no other abnormality and is not included).

Most of the abnormal test performances (22 of 35) were observed in the men with AIDS. Of the nine members of the other groups who performed abnormally, six had only an isolated abnormal result.
Computerised tomography detected evidence of disease of the central nervous system (CNS), in the most patients (9), but in one of them the disease was probably unrelated to HIV (a meningioma in a patient with AIDS). Neuropsychological testing showed abnormalities in six patients, all but two of whom also had abnormal computed tomograms. Electroencephalography also showed abnormal results in six men, four with unstable records and two with excessive theta activity.

This study shows that neurological and neuropsychological abnormalities, although occurring more commonly in patients with AIDS, are found at earlier stages of the syndrome. The research also shows the complexity of assessing the effect of HIV infection on the CNS, especially when clinical, neurological, neurophysiological, neuroradiological, and neuropsychological tests are performed and compared.

Clinical assessment and nerve conduction studies showed abnormalities of the peripheral nervous system in 11 patients, six of whom had AIDS. The finding that the latencies were not affected suggests that peripheral neuropathy that develops in AIDS patients is of axonal type. Inflammatory neuropathy has been described in patients with fever, night sweats, and lymphadenopathy. ${ }^{20}$ The changes seen in our patients, however, which were accompanied by no symptoms or only mild dysaesthesiae, seem more likely to be analogous to the symptomatic cases of distal symmetrical neuropathy..$^{2}$ No evidence was obtained concerning the aetiology of the neurological abnormalities. Cerebrospinal fluid was not examined, so the possible role of cytomegalovirus, for example, cannot be evaluated. The findings were, however, compatible with the early manifestations of encephalopathy or neuropathy that appear to be directly related to HIV itself.

In this study subclinical neurological dysfunction, which was believed to be caused by HIV, was observed in nine of the 11 AIDS patients and nine of the 20 other patients with antibody to HIV. This study shows the complexity of the task of assessing neurological and neuropsychological effects of HIV infection. Prospective evaluation, using electrophysiological and imaging techniques, is needed to investigate the natural history of such manifestations and to assess the effect of antiviral treatment.

This study was supported by the Middlesex Hospital and Medical School Research Appeal. CAC and the cohort studies are supported by the Medical Research Council and the Frances and Augustus Newman Foundation. IVDW is a Wellcome Trust senior lecturer in infectious diseases. 


\section{References}

1 Gajdusek DC, Amyx HL, Gibbs CJ, et al. Infection of chimpanzees by human T-lymphotropic retroviruses in brain and other tissues from AIDS patients. Lancet 1985; i:55-6.

2 Shaw GM, Harper ME, Hahn BH, et al. HTLV-III infection in brains of children and adults with AIDS encephalopathy. Science 1985;227:177-82.

3 Levy JA, Shimabukuro J, Hollander $\mathrm{H}$, et al. Isolation of AIDSassociated retroviruses from cerebrospinal fluid and brain of patients with neurological symptoms. Lancet 1985;ii:568-8.

4 Ho DD, Rota TR, Schooley RT. Isolation of HTLV-III from cerebrospinal fluid and neural tissues of patients with neurologic syndromes related to the acquired immunodeficiency syndrome. $N$ Engl J Med 1985;313:1493-7.

5 Resnick L, di Marzo-Veronese F, Schupback J, et al. Intra-bloodbrain-barrier synthesis of HTLV-III specific IgG in patients with neurologic symptoms associated with AIDS or AIDS related complex. N Engl J Med 1985;313:1498-504.

6 Goudsmit J, Wolters EC, Bakker M. Intrathecal synthesis of antibodies to HTLV-III in patients without AIDS or AIDS related complex. Br Med J 1986;292:1231-4.

7 Carne CA, Tedder RS, Smith A, et al. Acute encephalopathy coincident with seroconversion for anti-HTLV-III. Lancet 1985;ii:1206-8.

8 Denning DW, Anderson J, Rudge P, Smith H. Acute myelopathy associated with primary infection with human immunodeficiency virus. Br Med J 1987;294:143-4.

9 Piette AM, Tusseau F, Vignon D. Acute neuropathy coincident with seroconversion for anti-LAV/HTLV-III. Lancet 1986; i:852.

10 Snider WD, Simpson DM, Nielsen S. Neurological complications of acquired immune deficiency syndrome: analysis of 50 patients. Ann Neurol 1983;14:403-18.

11 Petito CK, Navia BA, Cho E-S, Jordan BD, George DC, Price RW. Vacuolar myelopathy pathologically resembling subacute combined degeneration in patients with the acquired immunodeficiency syndrome. $N$ Engl J Med 1985;312:874-9.

12 Levy RM, Bredesen DE, Rosenblum ML. Neurological manifestations of the acquired immunodeficiency syndrome (AIDS): experience at UCSF and review of the literature. $J$ Neurosurg 1985;62:475-95.

13 Yarchoan R, Berg G, Brouwers P, et al. Response of humanimmunodeficiency-virus-associated neurological disease to $3^{\prime}$ azido- 3'-deoxythymidine. Lancet 1987; i:132-5.

14 Rey A. L'examen clinique en psychologie. Paris: Presses Universitaires de France, 1964.

15 Newman S, Smith P, Joseph P, Ell P, Harrison M. Acute neuropsychological consequences of coronary artery bypass surgery. Current Psychological Research and Reviews 1987;6: $115-24$.

16 Reitan RM. Validity of the Trail Making Tests as an indication of organic brain damage. Perceptual and Motor Skills 1958;8: 271-6.

17 Costa L, Vaughan HG, Howitz M, Ritter W. Purdue pegboard as a predictor of the presence and laterality of cerebral lesions. Journal of Consulting Psychology 1963;27:133-7.

18 Lezak M. Neuropsychological assessment. New York: OUP, 1983.

19 Jordan BD, Navia BA, Petito C, Cho E-S, Price RW. Neurological syndromes complicating AIDS. Front Radiat Ther Oncol 1985; 19:82-7.

20 Lipkin WI, Parry G, Kiprov D, Abrams D. Inflammatory neuropathy in homosexual men with lymphadenopathy. Neurology 1985;35:1479-83. 